\title{
GESTÃO DE PROCESSOS E SISTEMAS PRODUTIVOS COM ROBÔS AUTÔNOMOS E COLABORATIVOS PARA PREVENIR DOENÇAS A SAÚDE DO TRABALHADOR NO ÂMBITO DIGITAL.
}

\author{
A. B.V. Junior ${ }^{1}{ }^{*} ;$ D. O. Brito ${ }^{1}$; J.P. Monteiro ${ }^{1 ;}$ R.A. Moura ${ }^{1}$ \\ 1 Faculdade de Tecnologia de São José dos Campos - Professor Jessen Vidal \\ Av. Cesare Mansueto Giulio Lattes, 1350 - Eugênio de Melo, São José dos Campos/SP, \\ CEP: 12247-014, Brasil. Telefone: (12) 3905-2423 \\ *aldemar.vieira@fatec.sp.gov.br
}

\begin{abstract}
RESUMO: Através de uma ótica inversa, este artigo aborda o tema da saúde e segurança ocupacional, voltada principalmente para a ergonomia e relacionada aos trabalhos de origem digitais onde, o trabalhador se expõe às atividades com esforços repetitivos de alta velocidade, mesmo que leve. Além do trabalho repetitivo, o trabalhador está constantemente em má postura nas suas células de trabalho, fazendo-o conviver com dores, na sua maioria, localizadas nos membros superiores que com o tempo evolui para um quadro crônico se tornando uma doença do trabalho, como por exemplo a lesão por esforços repetitivos. A adoção de ferramentas de automação ou robotização de atividade rotineiras, permitem um processo de automação robótica com reconhecimento óptico das letras e números, diminui significativamente os esforços de digitação humana e consequentemente as enfermidades dos trabalhadores.
\end{abstract}

PALAVRAS-CHAVE: Automação; Robô; Doença; Repetitivo.

\begin{abstract}
Through a reverse optics, this article addresses the topic of occupational health and safety, focused primarily on ergonomics and related to digital work where the worker is exposed to activities with repetitive efforts of high speed, even if light. In addition to the repetitive work, the worker is constantly badly placed in his work cells, causing him to live with pains, mostly located in the upper limbs that over time develops into a chronic illness becoming a work illness, such as repetitive strain injury. The adoption of routine automation or robotization tools allows a robotic automation process with optical recognition of letters and numbers, significantly reducing human typing efforts and consequently worker sickness.
\end{abstract}

KEYWORDS: Automation; Robot; Sickness; Repetitive.

\section{INTRODUÇÃO}

Segundo Marx (2002), o trabalho cria valor de uso indispensável à existência da sociedade humana. Nesse sentido o ser humano transforma a natureza pelo trabalho e ao modificar a natureza, coloca em movimento as capacidades do seu próprio corpo. Desde então, facilitar ou diminuir o esforço do trabalhador no processo de trabalho é o principal objetivo do desenvolvimento dos instrumentos de trabalho e que deve ser ajustado ao sistema produtivo.

Nesta perspectiva tradicional, a relação homem máquina é entendida de forma estática, ainda que sejam inclusos na concepção do posto de trabalho aspectos relacionados aos movimentos corporais como digitação excessiva, zonas de alcance entre outras, mais precisamente a frequência de movimentos, que são traduzidas em parâmetros espaciais. 
Nesses casos, típicos das situações de trabalho criadas pelas modernas tecnologias de automação, a análise da atividade, tal como vem sendo desenvolvida pela ergonomia francofônica, encontra espaço e mostra-se rica em possibilidades, sendo uma delas, a utilização de robôs digitais (RPA), que trabalham como robôs colaborativos assumindo as tarefas de repetição excessiva, liberando o ser humano para executar outras tarefas de maior valor cognitivo e tomar decisões, deixando de lado a exposição as doenças por esforços repetitivos.

No sentido ergonômico, as próprias intervenções práticas que tomam como objeto a concepção e melhoria de sistemas informatizados de controle de processos contínuos levantam questões imediatas como a melhor forma de configurar uma tela de controle, a filtragem das informações apresentadas, o grau de transparência das regras internas para implantação dos sistemas e finalmente o nível de qualificação dos operadores (KEYSER, 1988).

Na prática, surgem dificuldades que exigem reflexão sobre a natureza essencial de automatizar o trabalho de digitar, valendo-se da contribuição dos estudos empíricos e conceitos desenvolvidos no campo da ergonomia, que por premissa devem ser circunscritos nos projetos do posto de trabalho, incluindo-se as funções psicofisiológicas do trabalhador, a ergonomia, a antropometria, para melhoria das condições de trabalho relacionadas aos aspectos e dimensões posturais e dos esforços físicos, somatizadas a manuseabilidade de dispositivos operacionais para a realização do trabalho de processamento eletrônico de dados.

Esse trabalho objetiva favorecer o trabalho ergonômico, utilizando de ferramentas digitais que permitem automatizar processos de documentação corporativa, atualmente realizados por digitação humana por digitação robótica, com a aplicação do RPA (Robotic Process Automation) e OCR (Optical Character Recognition) no conceito da indústria 4.0 e da inteligência artificial.

\section{REVISÃO DA LITERATURA}

\subsection{Ergonomia}

A ergonomia teve sua origem com os estudos e pesquisas relacionados a área da fisiologia ao estudar fatores que causavam cansaço e consumo energético, que acabam por adoentar os envolvidos, como por exemplo postura incorretas no desenvolvimento de projetos. O objetivo da ergonomia é a adequação do local de trabalho, satisfação e o mínimo conforto dos indivíduos. A ergonomia deve ser prevista em projetos de produtos, máquinas, equipamentos e sistemas, para que possam complementar as habilidades e força humana (CORRÊA e BOLETTI, 2015; MOURA, et al, 2019).

\subsection{Automação Industrial}

Automação define-se como a substituição do trabalho humano por máquinas, sendo assim, é a operação de máquinas com a interação entre o sistema automatizado e o operador (RIBEIRO, 1999).

Para Silveira e Lima (2003) é um conjunto de técnicas destinadas a tornar automáticas as realizações de tarefas, trazendo a substituição do gasto com bioenergia humana, como os esforços musculares e mentais, por elementos eletromecânicos.

A automação industrial é dinâmica e vem sendo repensada em função do desenvolvimento das técnicas digitais, por outro lado, a automação se depara com inúmeros desafios, como por exemplo, a otimização de informação, no sentido de fornecer uma interface homem máquina apropriada. Nesse viés há a necessidade de se estabelecer critérios para detectar como deve ser feito a otimização das informações e seu respectivo registro (NEVES et al, 2007). 
As vantagens advindas da automação industrial são de altos níveis de precisão e sincronismo das máquinas, além de benefícios como eficiência, segurança, menor custo e maior produtividade (SILVEIRA e LIMA, 2003).

\subsection{Lesão por Esforço Repetitivo (LER)}

Patologias relacionadas ao trabalho necessitam de intervenção que vão muito além do tratamento clínico e cirúrgico tradicionais, pois precisam ter também significativas alterações impostas na vida cotidiana de seus portadores. Uma das patologias mais comuns é a Lesão por esforços repetitivos (LER). Agrupam-se como LER afecções que acometem tendões sinoviais, músculos, nervos, ligamentos de forma isolada ou associada. Vários são os fatores ligados ao trabalho que levam a ocorrência de LER como por exemplo, a repetitividade de movimentos, o comportamento postural inadequado, o esforço físico, entre outros (MERLO et al, 2001).

\subsection{Distúrbio Osteomuscular Relacionado ao Trabalho (DORT)}

O distúrbio osteomuscular relacionado ao trabalho (DORT) caracteriza-se pela ocorrência de sintomas variados, tais como dor, parestesia, sensação de peso, entre outros. Para ocorrência de DORT, não existe uma causa única, mas muitos são os fatores que podem estar sendo realizados no trabalho, nesse sentido a DORT pode se manifestar em diversos quadros clínicos, com diferentes sintomas (BRASIL, 2015).

\subsection{Processo de automação robótica (RPA - Robotic Process Automation)}

Na sua essência, o RPA é um conjunto de ferramentas (software) que podem ser usados para automatizar as tarefas habitualmente efetuadas por humanos, imitando as ações realizadas por esses e usando exatamente os mesmos sistemas e interfaces existentes. Embora o termo Robotic Process Automation (RPA) possa facilmente induzir a visão de robôs para executar tarefas geralmente realizadas por humanos, o significado real do conceito é a automatização das referidas tarefas através de soluções de software para realizar trabalhos repetitivos e de baixo valor agregado como por exemplo, a transferência e integração de dados provenientes de múltiplas fontes como e-mail, folhas de pagamento e cálculo para sistemas ERP ou CRM (LACITY e WILLCOCKS, 2016).

\subsection{Reconhecimento óptico de caracteres (OCR - Optical Character Recognition)}

A primeira geração de sistemas de OCR comerciais surgiram na década de 60. Esta geração de equipamentos OCR foi caracterizada principalmente pela leitura de um formato restrito de letras. Os símbolos eram especialmente desenhados para leitura dos equipamentos e os primeiros não tinham um formato muito natural. Com o passar do tempo, máquinas capazes de ler múltiplas fontes apareceram e conseguiam processar até dez tipos diferentes de fontes. A variedade de fontes era limitada pelo método de reconhecimento do padrão utilizado e sua identificação, através da comparação da imagem com o caractere de uma biblioteca de protótipos de imagens para cada caractere de cada fonte (EIKVIL, 1993).

A partir de 1985 surgem publicações e debates sobre a associação entre a tenossitose e o trabalho de digitação, resultando em uma Portaria governamental no 4.062 em 06 de agosto de 1987, pelo Ministério da Previdência e Assistência Social, reconhecendo a tenossitose como doença do trabalho, fase em que as comunicações de acidentes de trabalho concentravam-se especificamente na função de digitadores e assim no Brasil, a primeira referência oficial sobre a lesão por esforço repetitivo (LER) foi feita pela Previdência Social, com a terminologia tenossinovite do digitador (BRASIL, 2019). 
Nas Figura 1, pode-se observar algumas doenças por esforço repetitivo, LER/DORT que podem ser adquiridas com o trabalho de digitação excessiva.

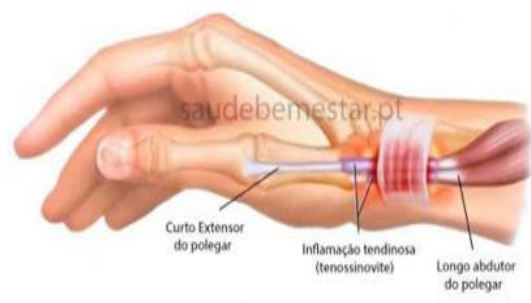

Tenossinovite Estenosante

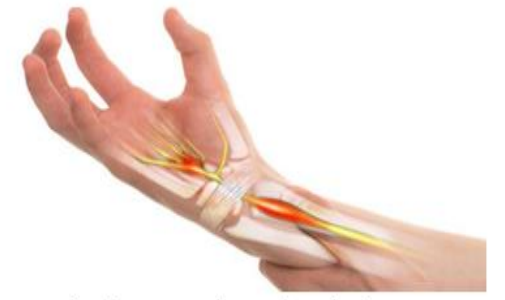

Síndrome do Túnel de Carpo

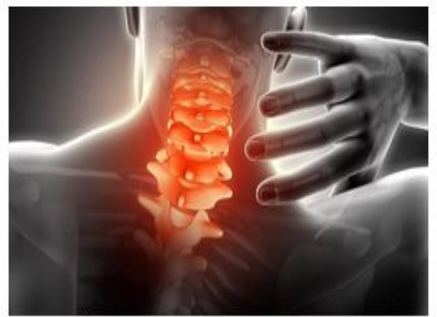

Síndrome Servical

(De Quervain)

Figura 1. Doenças oriundas de esforços repetitivos

Nessa linha da identificação do mal da digitação causa, é apontado pelo anuário de saúde do trabalhador de 2015, permitindo entender a gravidade da questão relacionada as doenças por esforços repetitivos e que estão diretamente relacionados aos trabalhos digitais de ambientes corporativos (FUNDACENTRO, 2019).

A Tabela 1 demonstra um histórico das notificações de agravos entre os anos de 2007 a 2014 da portaria ministerial, focando nas lesões por esforços repetitivos.

Tabela 1. Notificações de agravos relacionados ao trabalho por tipo

\begin{tabular}{lccccc|c|c}
\hline Ano & $\begin{array}{c}\text { Acidente } \\
\text { de } \\
\text { trabalho } \\
\text { grave }\end{array}$ & $\begin{array}{c}\text { Acidente de } \\
\text { trabalho com } \\
\text { exposição a } \\
\text { material } \\
\text { biológico }\end{array}$ & $\begin{array}{c}\text { Câncer } \\
\text { relaciona } \\
\text { do ao } \\
\text { trabalho }\end{array}$ & $\begin{array}{c}\text { Dermatoses } \\
\text { ocupacionais }\end{array}$ & $\begin{array}{c}\text { Lesões por } \\
\text { esforços } \\
\text { repetitivos }\end{array}$ & $\begin{array}{c}\text { Perda } \\
\text { auditiva } \\
\text { induzida } \\
\text { pelo ruído }\end{array}$ & Total \\
\hline 2007 & 19.725 & 15.735 & 5 & 128 & 3.228 & 113 & 38.934 \\
2008 & 31.317 & 24.704 & 12 & 299 & 3.474 & 204 & 60.010 \\
2009 & 35.321 & 30.197 & 30 & 392 & 4.690 & 258 & 70.888 \\
2010 & 44.767 & 34.883 & 26 & 507 & 5.951 & 329 & 86.463 \\
2011 & 60.921 & 40.400 & 126 & 685 & 7.191 & 559 & 109.882 \\
2012 & 73.896 & 45.102 & 72 & 1.017 & 8.258 & 412 & 128.757 \\
2013 & 87.994 & 48.499 & 147 & 987 & 8.073 & 657 & 146.357 \\
\hline & 79.649 & 47.292 & 170 & 679 & 7.737 & 784 & 136.311 \\
\hline
\end{tabular}

Das ocupações com o maior número de afastamento relacionados as doenças ocupacionais, pode-se destacar as ocupações que estão diretamente ligadas as atividades de repetição nas tarefas 
relacionadas ao trabalho de digitar, como por exemplo, a função de assistente administrativo, auxiliar de escritório e atividades afins.

Em continuidade, o Gráfico 1 compara as notificações entre o sexo masculino e o sexo feminino por tipo de agravo, demonstrando que o sexo feminino é quem mais sofre e está sujeita as lesões por esforços repetitivos, quando comparado ao sexo masculino.

Gráfico 1. Notificações de agravos relacionados ao trabalho por sexo.

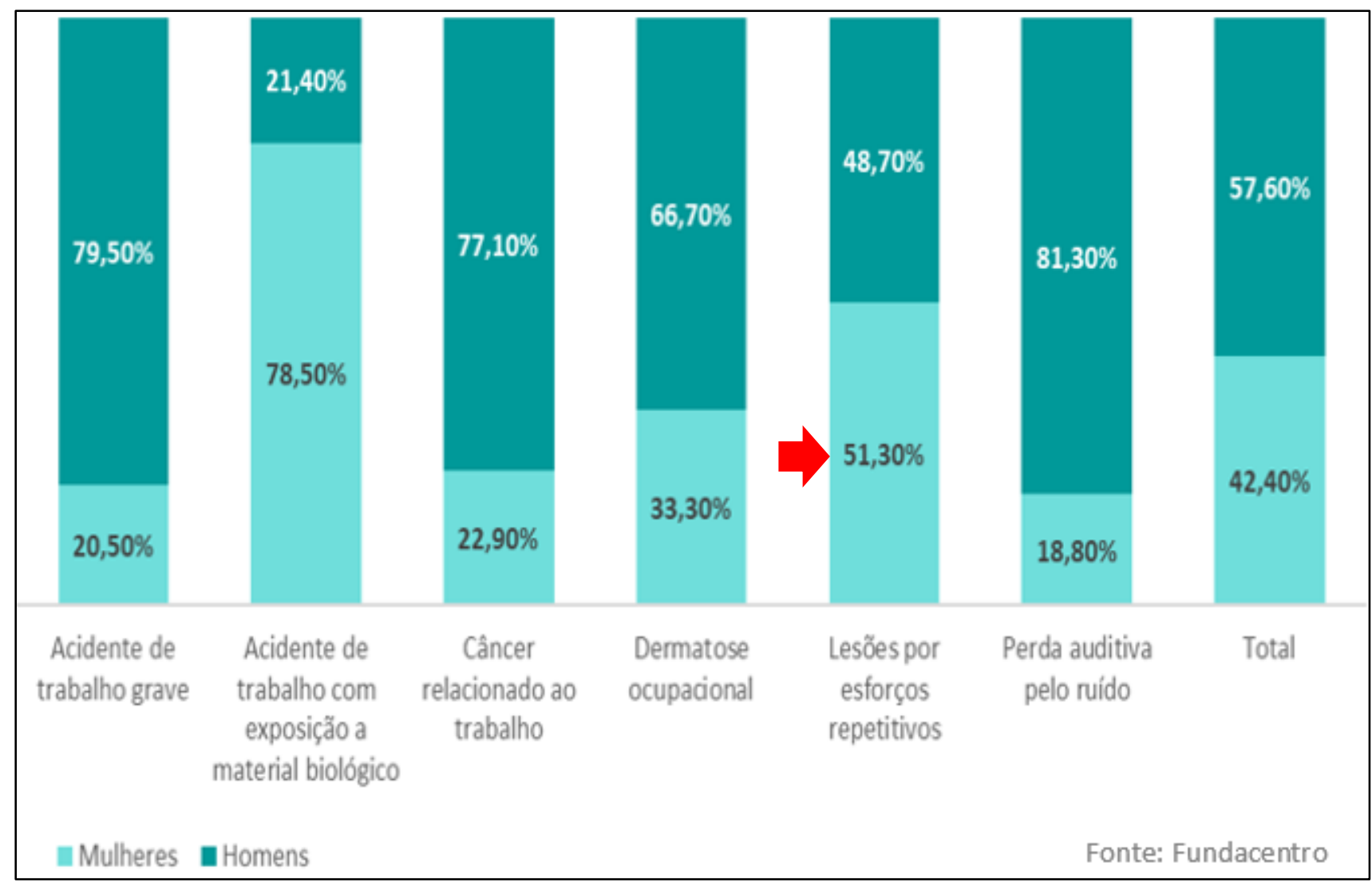

Os dados foram levantados através de uma pesquisa realizada pelo Jornal da Região em 24 de maio de 2019 nas principais cidades do Estado de São Paulo, revelando que nos últimos 10 anos o Brasil teve quase 70 mil casos de LER, e que das vítimas, 51,3\% eram do sexo feminino.

\subsection{A Robotização nas Indústrias}

Segundo Lacity e Willcocks (2016), a aplicação de robôs na linha de produção industriais permitiram automatizar as atividades repetitivas antes realizada por seres humanos. A interação humano-máquina, permite que o trabalho seja padronizado e ininterrupto, movimentos precisos e automatização dos movimentos repetitivos e sequenciais que passam a ser executadas por um robô colaborativo, garantindo assim que a operação seja contínua e seu processo com uma melhor qualidade e menores ou nenhum índice de retrabalho pós-processamento no produto acabado.

Na Figura 2 é demonstrado a contribuição para a ergonomia em atividades de difícil acesso, potencial de periculosidade e atividades altamente repetitivas, cujo resultado foi a redução no adoecimento dos trabalhadores. 


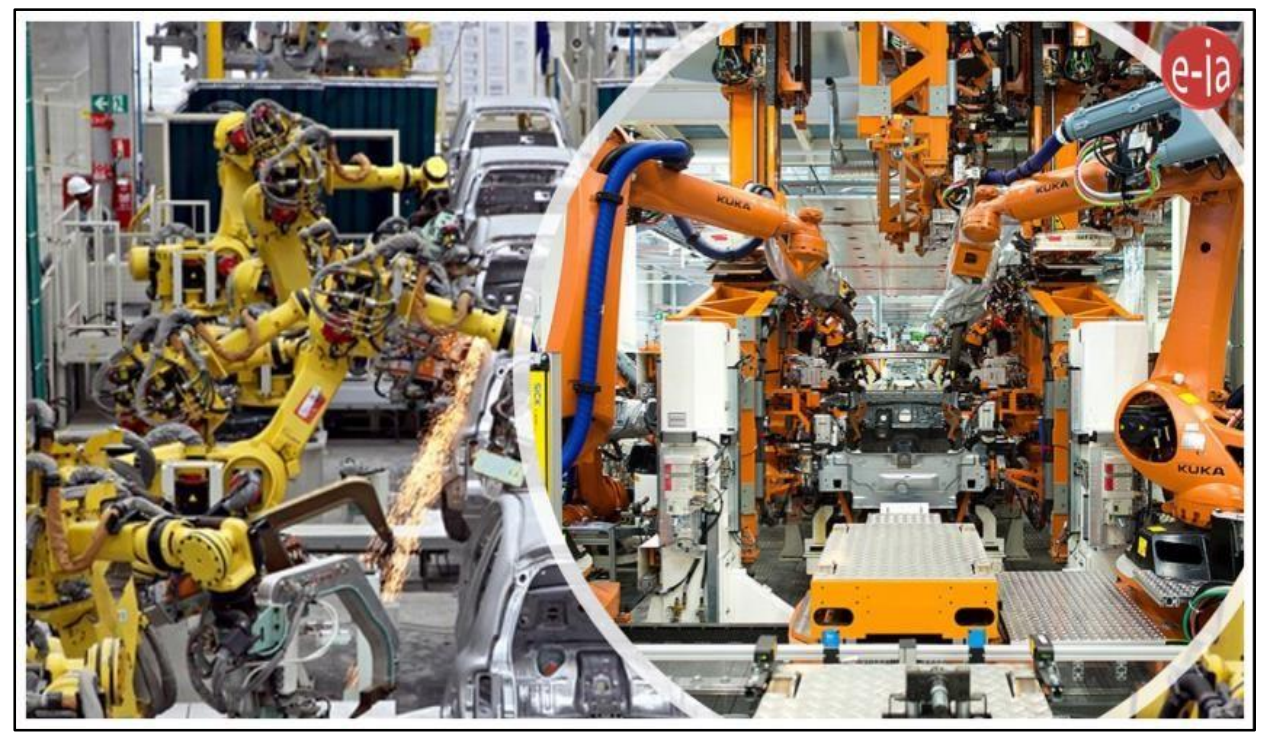

Figura 2. Automação no processo produtivo.

\section{MATERIAIS E MÉTODOS}

Para atender os objetivos deste trabalho, a metodologia de pesquisa utilizada foi estruturada utilizando ferramentas de RPA (Robotic Process Automation) e extração de dados através de sistema cognitivo OCR (Optical Character Recognition), imitando ao máximo as ações humanas em ler, comparar, copiar, colar, digitar, enviar e-mail, preencher campos em sistemas ERP/ECM, preencher células no Excel, utilizar de carimbos digitais, assinaturas digitais, fazer cálculos entre outros.

A interação humano-máquina na digitação de dados, permite que muitas atividades sejam automatizadas pela ferramenta RPA, como as demonstradas na Figura 3.

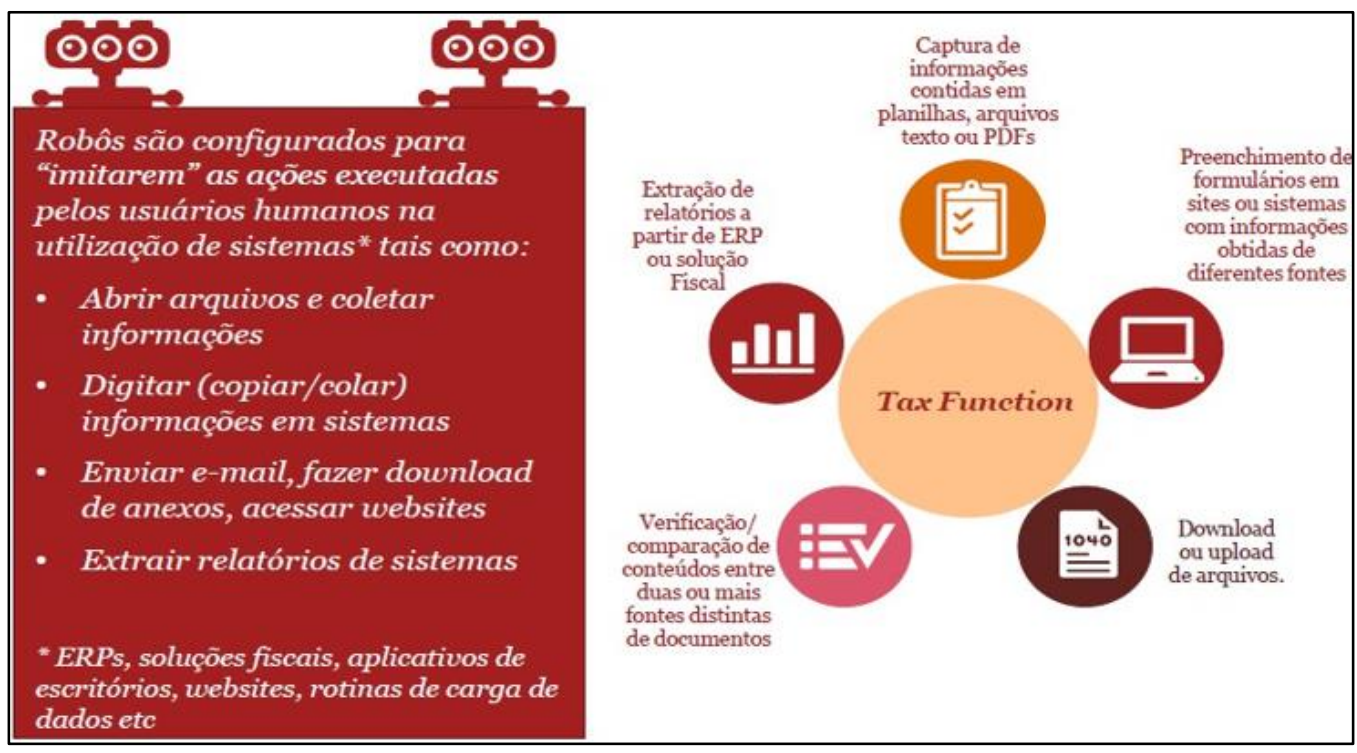

Figura 3. Atividades repetitivas possíveis de serem automatizadas. 
Na Figura 4, um fluxograma representa a tarefa de cadastramento de novos funcionários de uma grande empresa sobre os benefícios oferecidos por ela para a inclusão dos dados recebidos.

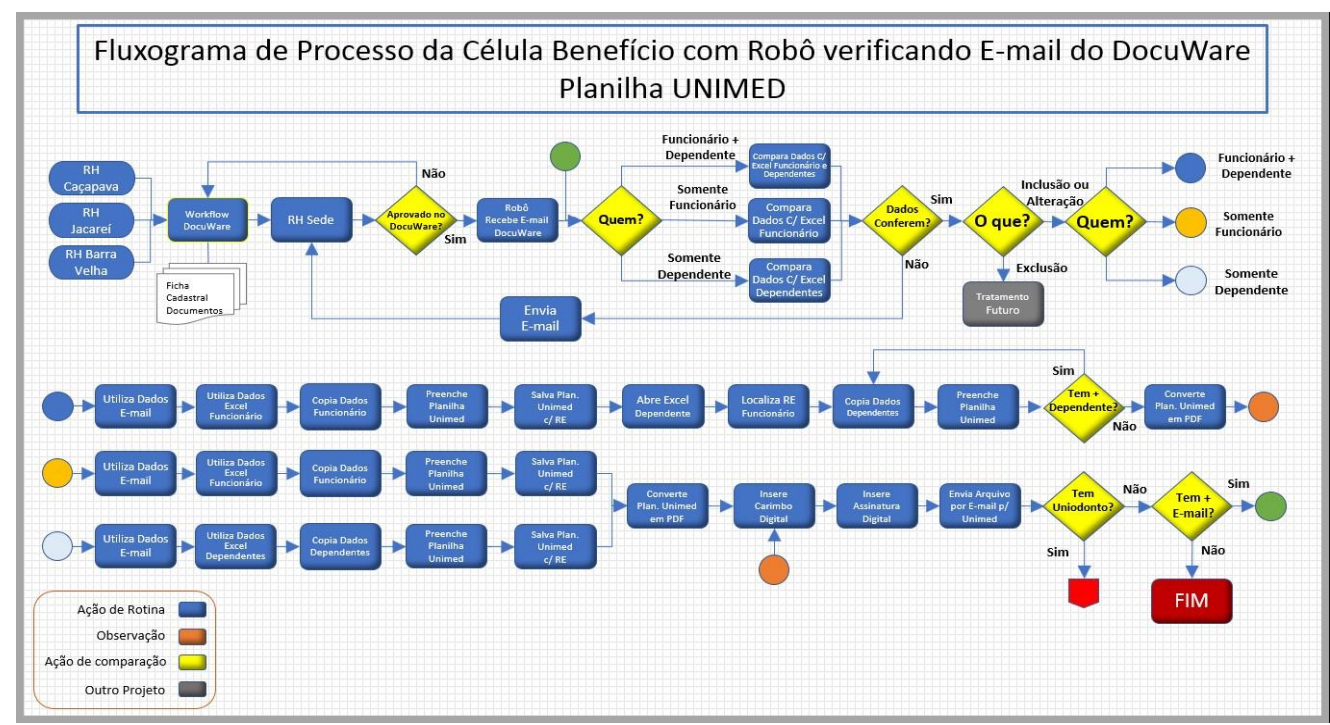

Figura 4. Fluxograma para cadastramento de novos colaboradores digitadores

O fluxograma da Figura 5, representa exatamente um processo de leitura de faturas de transporte internacional com valores em dólar a serem convertidos para reais, verificações de valores e lançamento dos valores convertidos em reais, no sistema SAP.

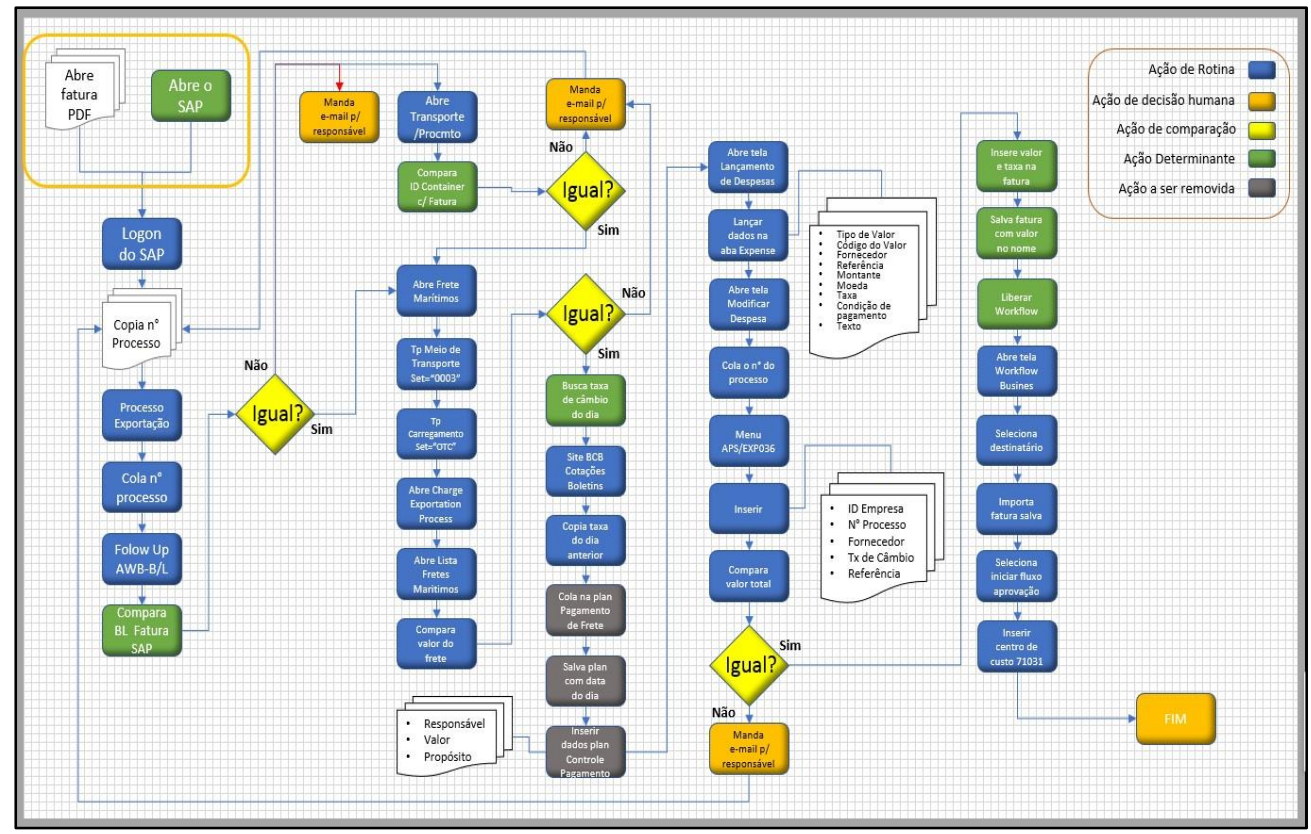

Figura 5. Fluxograma de processo para lançamento de valores de fatura no SAP. 


\section{RESULTADOS E DISCUSSÕES}

No processo da célula de benefícios, mostrado na Figura 3, encontramos uma situação, onde uma funcionária da sede da empresa, tinha como tarefa, incluir os novos funcionários de todas as unidades da companhia nos benefícios de saúde, odontologia e farmácia.

Para cada funcionário, foram computados 630 movimentos repetitivos entre movimentar mouse, abrir sistemas, localizar funcionário no sistema ERP da empresa, copiar dados, colar dados e alternar entre telas. Em média, se cadastra 10 novos colaboradores por dia totalizando em torno de 6300 movimentos repetitivos somente para essa atividade diária.

No processo de lançamento de faturas referentes ao transporte marítimo, mostrada na Figura 7 , dois funcionários tinham apenas três horas do dia para fazer o máximo de lançamentos convertidos de Dólar para Real no sistema SAP da empresa.

Em ambos os processos utilizamos das ferramentas RPA e OCR, nos possibilitando automatizar $100 \%$ deste processo, liberando o funcionário de uma carga excessiva de repetições relacionadas a esforções repetitivos. E consequentemente, diminuir a incidência a exposição as doenças relacionadas ao trabalho.

\section{CONCLUSÃO}

A automação de processos e a robotização sempre estão ligados a dois olhares da sociedade. Aumento da produção, diminuição de custos e maior lucratividade das empresas. E a consequência negativa para aqueles que irão perder seus empregos para uma máquina. Mas, desenvolvemos este trabalho com um olhar transversal, mostrando o benefício que a automação e robotização de processos traz para o colaborador quando relacionamos a uma melhor qualidade de vida, libertando o ser humano de trabalhos repetitivos que desgastam as fibras musculares e muitas vezes em condições irreversíveis. Trazendo dores e desconfortos permanentes, prejudicando-o não somente fisicamente, mas também psicologicamente. Portanto, demonstramos com clareza que tarefas repetitivas dentro de um processo no âmbito do trabalho digital podem ser substituídas por um robô aliado de outras ferramentas, criando assim, um ecossistema capaz de livrar o ser humano em até $100 \%$ de atividades causadoras de doenças ocupacionais como a LER e a DORT.

\section{REFERÊNCIAS}

BRASIL. 2015. Ministério da Saúde. Protocolo de investigação, diagnóstico, tratamento e prevenção de lesões por esforços repetitivos: LER/DORT distúrbios osteomusculares relacionados ao trabalho. Brasília: Ministério da Saúde.

BRASIL, 2019. Portarias de 19 de dezembro de 2018. Disponível em: http://www.in.gov.br/materia//asset_publisher/Kujrw0TZC2Mb/content/id/58200528. Acesso em 26/06/2019.

CORRÊA, V. M.; BOLETTI, R. R. Ergonomia: Fundamentos e aplicações. Editora ABDR, 2015.

EIKVIL, L. OCR Optical Character Recognition, 1993. 
FUNDACENTRO, 2019. Anuário do trabalhador. Disponível em: http://www.fundacentro.gov.br/. Acesso em 26/06/2019.

JORNAL DA REGIÃO, Em 10 anos, pais teve quase 70 mil casos de LER. Disponível em: https://www.jr.jor.br/2019/05/24/em-10-anos-pais-teve-quase-70-mil-casos-de-ler/. Acesso em 26/06/2019

KEYSER, V. De la contingence à la compléxité: l'évolution des idées dans l'étude des processus continus. Le Travail Humain. 51(1):1-18. 1988.

LACITY, M. C., and WILlCOCKS, L. P. A New Approach to Automating Services. MIT Sloan Management Review, 58(1), 40-49. (2016a).

\section{LIMA, F. De P. A. ERGONOMIA DAS NOVAS TECNOLOGIAS:}

Saber prático e objetivação do conhecimento. Departamento de Engenharia de Produção - UFMG - CP 209 - Belo Horizonte/MG

MARX, K. O capital: crítica da economia política (vols. 1 e 2). Rio de Janeiro: Civilização Brasileira. (2002).

MERLO, Á. R. C.; JACQUES, M. Da G. C.; HOEFEL, M. Da G. L. Trabalho de grupo com portadores de LER/DORT: Relato de Experiência. Disponível em: http://www.scielo.br/pdf/\%0D/prc/v14n1/5223. Acesso em: 12/06/2019.

MOURA, R. A.; JESUS, N. M. R.; SOUZA, R. S. Antropometria e ergonomia como ferramentas de vanguarda produtivas nas indústrias do futuro. Revista Sodebrás. Volume $\mathrm{n}^{\circ} 14$. Edição $\mathrm{n}^{\circ}$ 157. Janeiro/2019, p.109-112. ISSN. 1809-3957. DOI: https://doi.org/10.29367/issn.1809$\underline{3957.2019 .157}$

NEVES, C.; DUARTE, L.; VIANA, N.; LUCENA JR, V.F. Os dez maiores desafios da automação industrial: As perspectivas para o futuro. Disponível em:

https://www.researchgate.net/profile/Vicente_Lucena_Jr/publication/324452815_OS_DEZ_MAIO RES_DESAFIOS_DA_AUTOMACAO_INDUSTRIAL_AS_PERSPECTIVAS_PARA_O_FUTU RO/links/5ace3247aca2723a3341c31b/OS-DEZ-MAIORES-DESAFIOS-DA-

AUTOMACAOINDUSTRIAL-AS-PERSPECTIVAS-PARA-O-FUTURO.pdf. Acesso em: $12 / 06 / 2019$.

RIBEIRO, M. A. Automação Industrial. Disponível em: http://www.academia.edu/download/45282151/16247325-Automacao-Industrial-Livro.pdf. Acesso em: $12 / 06 / 2019$.

SILVEIRA, L.; LIMA, W. Q. Um breve histórico conceitual da automação industrial e redes para automação industrial. Disponível em:

https://s3.amazonaws.com/academia.edu.documents/43839581/Redes_Industriais_e_Automacao.pd f?response-content-

disposition=inline\%3B\%20filename\%3DUm_breve_historico_conceitual_da_Automac.pdf\&XAmz -Algorithm=AWS4-HMAC-SHA256\&X-Amz- 


\section{ISSN $2447-5378$}

Credential=AKIAIWOWYYGZ2Y53UL3A\%2F20190612\%2Fus-east-

1\%2Fs3\%2Faws4_request $\& X-A m z-D a t e=20190612 T 143619 Z \& X-A m z-E x p i r e s=3600 \& X-$ AmzSignedHeaders $=$ host $\&$ X-

AmzSignature $=2 \mathrm{f} 8 \mathrm{dd} 795 \mathrm{c} 0079523 \mathrm{db} 4 \mathrm{~b} 97 \mathrm{eb} 32 \mathrm{~d} 960 \mathrm{a} 54 \mathrm{a} 550412027 \mathrm{bd} 8 \mathrm{e} 37 \mathrm{e} 93267 \mathrm{~d} 2 \mathrm{~d} 41 \mathrm{~d} 698$. Acesso em: 12/06/2019. 